\title{
DETERMINATION OF ACCURACY AND RELIABILITY OF PORTABLE HARDNESS TESTERS
}

doi: 10.2478/cqpi-2019-0039

Date of submission of the article to the Editor: 03/05/2019

Date of acceptance of the article by the Editor: 31/05/2019

\author{
Alan Vaško ${ }^{1}$ - orcid id: 0000-0002-3937-2691 \\ Ján Sovík ${ }^{1}$ - orcid id: 0000-0001-6964-9658 \\ Marek Krynke ${ }^{2}$ - orcid id: 0000-0003-4417-1955 \\ 1 University of Žilina, Slovakia \\ ${ }^{2}$ Czestochowa University of Technology, Poland
}

\begin{abstract}
The paper is focused on determination of the accuracy and reliability of static and dynamic (portable) hardness testers. The paper deals with the measurement of hardness of calibration hardness plates by 4 different methods (Brinell, Vickers, Rockwell and Leeb) with using 5 different hardness testers ( 3 static and 2 portable). The hardness values measured by the different hardness testers were compared to the reference hardness listed in the calibration hardness plates and consequently, the accuracy of these measurements was evaluated. The aim of the work has been to determine the accuracy and reliability of portable hardness testers in comparison with static hardness testers.
\end{abstract}

Keywords: hardness, Brinell, Vickers, Rockwell, Leeb

\section{INTRODUCTION}

Hardness is a mechanical property of a material defined as the resistance of a material to the permanent deformation of its surface caused by the effect of a geometrically defined body. In the hardness test, the surface of the test material is mechanically loaded by the pressure of the foreign body from the hard material and the result of this action is quantitatively expressed as the hardness value.

Nowadays, several methods for hardness testing are used in practice (Herrmann, 2011; Chandler, 2004; Kuhn, 2000). Hardness tests are divided:

- according to the principle (indentation, rebound, scratch and pendulum methods),

- according to the speed of the loading force (static and dynamic methods),

- according to the purpose of hardness measurement (macro and microhardness tests).

According to the principle, indentation and rebound methods are most widely used. The principle of indentation methods consists in pushing the indentor (ball, pyramid, cone) of steel, carbide or diamond into the test material, where the criterion for determination of hardness is the size of the indentation (Brinell, Vickers, Rockwell and Knoop method). The principle of rebound methods consists in rebounding of the 
falling body of a certain shape and weight from the test material, where the criterion for determination of hardness is the height of rebound (Shore method) or the energy loss (Leeb method) (Vaško, 2014; Skočovský, 2015; Belan, 2012; Borkowski, 2009). In static methods, the test material is loaded slowly, continuously, with a uniformly increasing load (Brinell, Vickers, Rockwell and Knoop method); in dynamic methods, the load increases suddenly, by impact (Leeb method) (Borggreen, 2001).

For laboratory hardness testing, there are usually used table hardness testers which use static methods. For exterior hardness testing, there are increasingly used universal portable hardness testers that use dynamic methods. These hardness testers enable the measured hardness to be converted to all common hardness scales (HB, HV, HRB, HRC, HS) as well as the orientation tensile strength $R_{m}$. For this reason, the paper deals with comparing the accuracy and reliability of static (table) and dynamic (portable) hardness testers (Smejkal, 2007; Zat'ko, 2009).

\section{METHODOLOGY OF RESEARCH}

Hardness tests were carried out at the Department of Materials Engineering, Faculty of Mechanical Engineering, University of Žilina.

The following methods were used for experiments (hardness tests) -3 static methods (Brinell, Vickers and Rockwell) and 1 dynamic method (Leeb).

Five hardness testers were used for experiments:

- for Brinell hardness test - table hardness tester CV-3000LDB;

- for Vickers hardness test - table hardness tester HPO250/AQ;

- for Rockwell hardness test - table hardness tester RR-1D/AQ;

- for Leeb hardness test - portable hardness testers TH170 and TH1100 (Fig. 1).

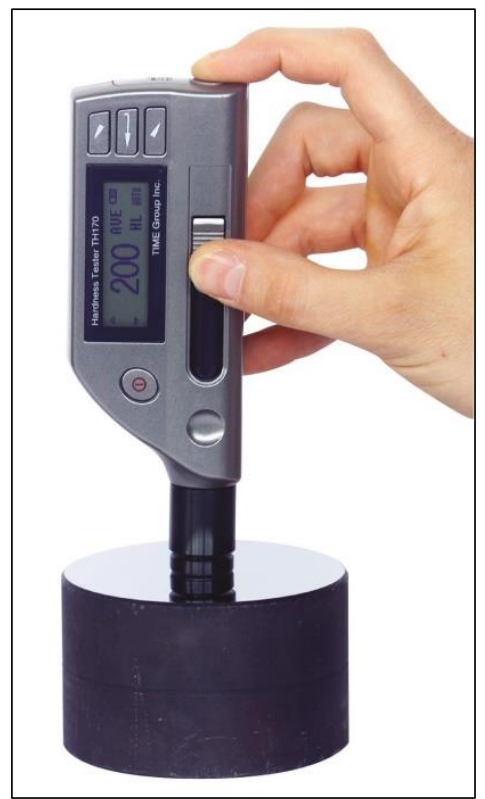

a) $\mathrm{TH} 170$

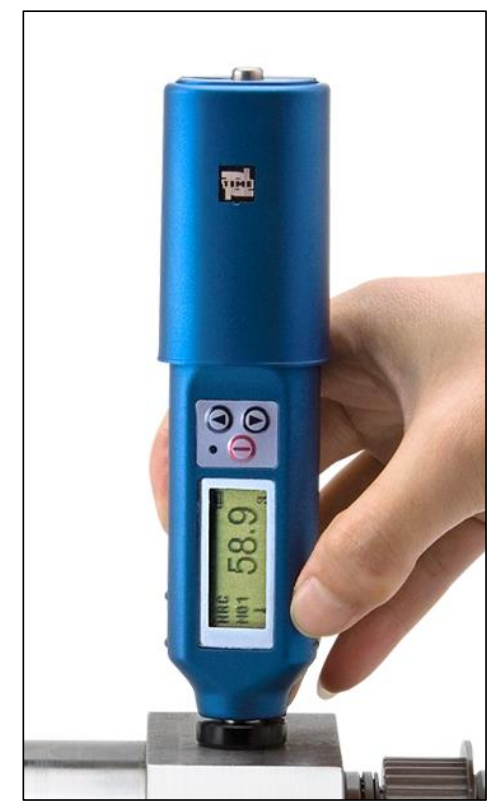

b) $\mathrm{TH} 1100$

Fig. 1. Portable hardness testers

Four hardness calibration plates were used as experimental material for hardness tests:

- for Brinell hardness test - hardness plate with hardness 97.4 HBW 5/250;

- for Vickers hardness test - hardness plate with hardness 710 HV 30; 
- for Rockwell hardness test - hardness plate with hardness 64.4 HRC;

- for Leeb hardness test - hardness plate with hardness 778 HLD.

The following conditions were used for hardness tests:

- for Brinell hardness test (according to STN EN ISO 6506-1) - carbide ball with diameter $D=5 \mathrm{~mm}$, test load $F=250 \mathrm{kp}(2452.5 \mathrm{~N})$, loading time $t=10 \mathrm{~s}=>\mathrm{HBW}$ $5 / 250 / 10$;

- for Vickers hardness test (according to STN EN ISO 6507-1) - diamond regular quadrilateral pyramid, load $F=30 \mathrm{kp}(294.3 \mathrm{~N})$, loading time $\mathrm{t}=10 \mathrm{~s}=>\mathrm{HV} 30 / 10$;

- for Rockwell hardness test (according to STN EN ISO 6508-1) - diamond cone, load $\mathrm{F}=150 \mathrm{kp}(1471.5 \mathrm{~N})$, loading time $\mathrm{t}=6 \mathrm{~s}=>\mathrm{HRC}$;

- for Leeb hardness test (according to STN EN ISO 16859-1) - carbide ball with diameter $\mathrm{D}=3 \mathrm{~mm}=>$ HLD.

Each calibration hardness plate was subjected to 5 measurements using a table hardness tester and another 5 measurements using portable hardness testers. The average value $\overline{\mathrm{H}}$ and standard deviation $\mathrm{s}_{\mathrm{x}}$ were calculated from the measured values. From the average hardness $\overline{\mathrm{H}}$ and reference hardness $\mathrm{H}_{\text {ref }}$ listed on the calibration hardness plate, the measurement inaccuracy was calculated according to the formula (1):

$$
\mathrm{N}=\frac{\overline{\mathrm{H}}-\mathrm{H}_{\text {ref }}}{\mathrm{H}_{\mathrm{ref}}} \cdot 100
$$

\section{RESULTS AND DISCUSSION}

The results of hardness measurement on the hardness plate for Brinell hardness test are given in Tab. 1. Table hardness tester CV-3000LDB and portable hardness testers $\mathrm{TH} 170$ and $\mathrm{TH} 1100$ were used for measurement.

Table 1

Results of Brinell hardness test

\begin{tabular}{|c|c|c|c|c|}
\hline Hardness tester & \multicolumn{2}{|c|}{ CV-3000LDB } & TH170 & TH1100 \\
\hline Measurement No & $d(\mathrm{~mm})$ & HBW5/250/10 & HB (HLD) & HB (HLD) \\
\hline 1 & 1.78 & 98 & 91 & 95 \\
\hline 2 & 1.80 & 95 & 92 & 91 \\
\hline 3 & 1.78 & 98 & 96 & 93 \\
\hline 4 & 1.79 & 96 & 97 & 90 \\
\hline 5 & 1.80 & 95 & 92 & 89 \\
\hline$\overline{\mathrm{H}}$ & & 96.4 & 93.6 & 91.6 \\
\hline$S_{x}$ & & 1.52 & 2.70 & 2.41 \\
\hline $\mathrm{N}(\%)$ & & -1.03 & -3.90 & -5.95 \\
\hline
\end{tabular}

A comparison of the results of Brinell hardness test is shown in Fig. 2a. The hardness measured by the table hardness tester differs from the reference hardness minimally $(-1.03 \%)$. The hardness determined by the portable hardness testers differs from the reference hardness by $-3.90 \%$, respectively $-5.95 \%$. The values measured by the table hardness tester show less inaccuracy than the values measured by the portable hardness testers (Tab. 1) 
The results of hardness measurement on the hardness plate for Vickers hardness test are given in Tab. 2. Table hardness tester HPO250/AQ and portable hardness testers $\mathrm{TH} 170$ and $\mathrm{TH} 1100$ were used for measurement.

Table 2

Results of Vickers hardness test

\begin{tabular}{|l|l|l|l|l|}
\hline Hardness tester & \multicolumn{1}{|c|}{ HPO250/AQ } & \multicolumn{1}{c|}{ TH170 } & \multicolumn{1}{c|}{ TH1100 } \\
\hline Measurement No & \multicolumn{1}{|c|}{$\mathbf{d}(\mathbf{m m})$} & \multicolumn{1}{c|}{ HV30/10 } & HV (HLD) & \multicolumn{1}{c|}{ HV (HLD) } \\
\hline 1 & 0.275 & 736 & 742 & 703 \\
\hline 2 & 0.275 & 736 & 706 & 698 \\
\hline 3 & 0.276 & 730 & 731 & 689 \\
\hline 4 & 0.274 & 741 & 735 & 691 \\
\hline 5 & 0.274 & 741 & 740 & 707 \\
\hline $\bar{H}$ & & 736.8 & 730.8 & 697.6 \\
\hline $\mathrm{S}_{\mathrm{x}}$ & 4.55 & 14.52 & 7.67 \\
\hline $\mathrm{N}(\%) \quad$ & +3.77 & +2.93 & -1.75 \\
\hline \multicolumn{5}{|l}{} \\
\hline
\end{tabular}

A comparison of the results of Vickers hardness test is shown in Fig. $2 b$. The hardness measured by the table hardness tester differs from the reference hardness by $+3.77 \%$. The hardness determined by the portable hardness testers differs from the reference hardness by $+2.93 \%$, respectively $-1.75 \%$. The values measured by the portable hardness testers show less inaccuracy than the values measured by the table hardness tester (Tab. 2).

The results of hardness measurement on the hardness plate for Rockwell hardness test are shown in Tab. 3. Table hardness tester RR-1D/AQ and portable hardness testers TH170 and TH1100 were used for measurement.

Table 3

Results of Rockwell hardness test

\begin{tabular}{|l|l|l|l|}
\hline Hardness tester & \multicolumn{1}{|c|}{ RR-1D/AQ } & \multicolumn{1}{c|}{ TH170 } & \multicolumn{1}{c|}{ TH1100 } \\
\hline Measurement No & \multicolumn{1}{|c|}{ HRC } & \multicolumn{1}{c|}{ HRC (HLD) } & HRC (HLD) \\
\hline 1 & 64.1 & 62.4 & 60.4 \\
\hline 2 & 64.8 & 58.6 & 59.0 \\
\hline 3 & 64.6 & 61.6 & 60.9 \\
\hline 4 & 64.5 & 60.5 & 60.1 \\
\hline 5 & 64.7 & 63.2 & 60.3 \\
\hline $\bar{H}$ & 64.5 & 61.3 & 60.2 \\
\hline $\mathrm{S}_{\mathrm{x}}$ & 0.27 & 1.79 & 0.71 \\
\hline $\mathrm{N}(\%)$ & -4.81 & -6.52 \\
\hline \multicolumn{2}{|l|}{ reference hardness Href from the calibration hardness plate $=>64.4 \mathrm{HRC}$} \\
\hline
\end{tabular}

A comparison of the results of Rockwell hardness test is shown in Fig. 2c. The hardness measured by the table hardness tester differs from the reference hardness minimally $(+0.22 \%)$. The hardness determined by the portable hardness testers differs from the reference hardness by $-4.81 \%$, respectively $-6.52 \%$. The values measured by the table hardness tester show less inaccuracy than the values measured by the portable hardness testers (Tab. 3). 
The results of hardness measurement on the hardness plate for Leeb hardness test are given in Tab. 4. Portable hardness testers TH170 and $\mathrm{TH} 1100$ were used for measurement.

Table 4

Results of Leeb hardness test

\begin{tabular}{|l|l|l|}
\hline Hardness tester & \multicolumn{1}{|c|}{ TH170 } & \multicolumn{1}{c|}{ TH1100 } \\
\hline Measurement No & \multicolumn{1}{|c|}{ HLD } & \multicolumn{1}{c|}{ HLD } \\
\hline 1 & 777 & 784 \\
\hline 2 & 781 & 784 \\
\hline 3 & 785 & 785 \\
\hline 4 & 782 & 780 \\
\hline 5 & 780 & 783 \\
\hline $\bar{H}$ & 781.0 & 783.2 \\
\hline $\mathrm{S}_{\mathrm{x}}$ & 2.92 & 1.94 \\
\hline $\mathrm{N}(\%) \quad$ & +0.64 \\
\hline \multicolumn{2}{|l|}{ reference hardness $\mathrm{H}_{\mathrm{ref}}=>778 \mathrm{HLD}$} \\
\hline
\end{tabular}

A comparison of the results of Leeb hardness test is shown in Fig. 2d. The hardness determined by the portable hardness testers differs from the reference hardness by less than $1 \%(+0.38 \%$, respectively $+0.64 \%)$ (Tab. 4$)$.

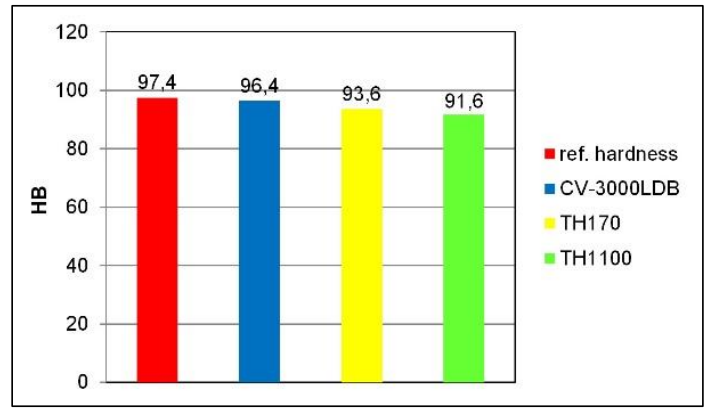

a) Brinell hardness test

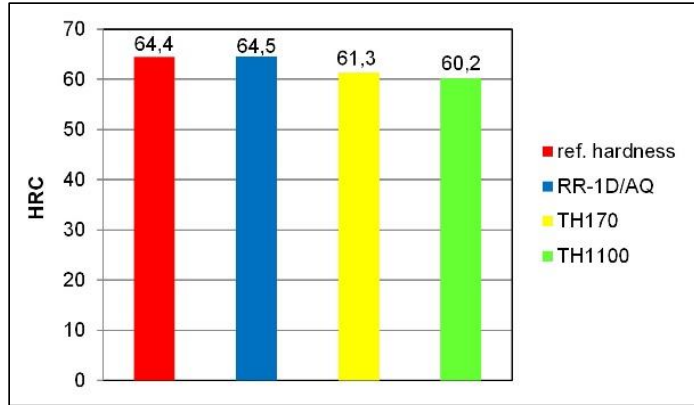

c) Rockwell hardness test

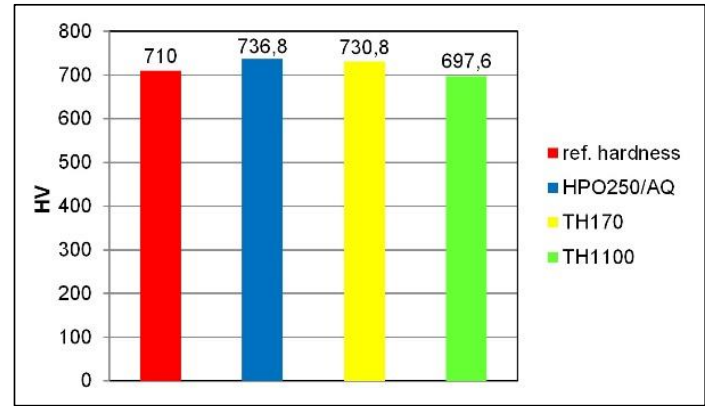

b) Vickers hardness test

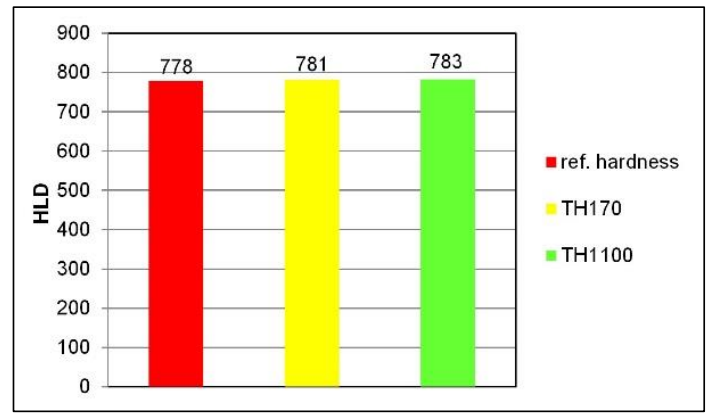

d) Leeb hardness test

Fig. 2. Comparison of measured hardness with reference hardness

By comparing the table hardness testers (Tab. 1-3), it was found that the lowest inaccuracy $\mathrm{N}$ (percentage deviation between measured and reference hardness) was achieved by the hardness tester RR-1D/AQ for Rockwell hardness test $(+0.22 \%)$, followed by the hardness tester CV-3000LDB for Brinell hardness test $(-1.03 \%)$ and finally by the hardness tester HPO250/AQ for Vickers hardness test $(+3.77 \%)$. 
Using portable hardness testers (Tab. 1-4), the lowest inaccuracy $N$ was achieved for Vickers hardness test $(+2.93 \%$ by the hardness tester $\mathrm{TH} 170$, respectively $-1.75 \%$ by the hardness tester $\mathrm{TH} 1100)$, followed by Brinell hardness test $(-3.90 \%$ by the hardness tester $\mathrm{TH} 170$ and $-5.95 \%$ by the hardness tester $\mathrm{TH} 1100)$ and by Rockwell hardness test $(-4.81 \%$ by the hardness tester $\mathrm{TH} 170$ and $-6.52 \%$ by the hardness tester TH1100). For the Leeb hardness test, the inaccuracy of measurement was minimal in both cases $(+0.38 \%$, respectively $+0.64 \%)$.

By comparing the portable hardness testers, it was found that the hardness tester TH170 was more accurate for Brinell hardness test (inaccuracy $-3.90 \%$ ), Rockwell hardness test $(-4.81 \%)$ and Leeb hardness test $(+0.38 \%)$; the hardness tester TH1100 was more accurate only for Vickers hardness test $(-1.75 \%)$.

In the case of Brinell hardness test, the table hardness tester CV-3000LDB was significantly more accurate (inaccuracy $-1.03 \%$ ) than the portable hardness testers. Similarly, for Rockwell hardness test, the table hardness tester RR-1D/AQ was significantly more accurate $(+0.22 \%)$ compared to the portable hardness testers. Only for Vickers hardness test, the portable hardness testers $\mathrm{TH} 170$ and $\mathrm{TH} 1100$ were more accurate $(+2.93 \%$, respectively $-1.75 \%)$ compared to the table hardness tester HPO250/AQ. In this case, it would be necessary to calibrate the table hardness tester to increase its accuracy.

\section{CONCLUSION}

The paper is focused on determination of the accuracy and reliability of static (table) and dynamic (portable) hardness testers. The paper deals with the measurement of hardness of calibration hardness plates by 4 different methods (Brinell, Vickers, Rockwell and Leeb) with using 5 different hardness testers ( 3 table and 2 portable). The hardness values measured by the different hardness testers were compared to the reference hardness listed in the calibration hardness plates and consequently, the accuracy of these measurements was evaluated.

The hardness tests carried out with using table and portable hardness testers showed that more accurate values of hardness were obtained using table hardness testers. The accuracy and reliability of portable hardness testers was lower than that of table hardness testers. This accuracy can be influenced by different method of measuring and by the need to convert the measured Leeb hardness to other hardness scales. On the other hand, portable hardness testers have several advantages, such as measuring hardness outside the laboratory, measuring large and heavy test specimens (that cannot be measured with table hardness testers), measuring hardness in different directions, lower cost of hardness testing, etc.

\section{ACKNOWLEDGEMENTS}

The research has been supported by the Scientific Grant Agency of Ministry of Education, Science, Research and Sport of Slovak Republic, grant project VEGA No. $1 / 0398 / 19$ and by the Culture and Educational Grant Agency of Ministry of Education, Science, Research and Sport of Slovak Republic, grant projects KEGA No. 049ŽU4/2017 and 012ŽU-4/2019.

\section{REFERENCES}

Belan, J., 2012. Study of advanced materials for aircraft jet engines using quantitative metallography. Recent Advances in Aircraft Technology, Rijeka, Croatia, 49-74. 
Borggreen, K., Auerkari, P., 2001. Performance of some portable hardness testers. Baltica V - Condition and life management for power plants, Porvoo, Finland, 559574.

Borkowski, S., Ulewicz, R., 2009. Laboratorium z materiałoznawstwa dla inżynierów, CWA, Częstochowa, Poland.

Chandler, H., 2004. Hardness testing, ASM International, Materials Park, Ohio, USA.

Herrmann, K., 2011. Hardness testing - principles and applications, ASM International, Materials Park, Ohio, USA.

Kuhn, H., Medlin, D., 2000. ASM Handbook, Vol. 8: Mechanical testing and evaluation, ASM International, Materials Park, Ohio, USA.

Smejkal, J., 2007. Measurement of hardness according to ASTM A 956-00. Available on: http://www.testima.eu/prilohy/149/astm956.pdf

Skočovský, P., Bokůvka, O., Konečná, R., Tillová, E., 2015. Materialscience, EDIS, Žilina, Slovakia.

Vaško, A., Skočovský, P., 2014. Properties and using of metal materials, EDIS, Žilina, Slovakia.

Zat'ko, M., Eckhardt, E., 2009. Methods of measuring hardness of materials and principles of choosing portable equipments for measurement. Available on: http://www.ssndt.sk/files/odborne/Zakladne\%20zasady\%201.pdf 